\title{
Processes of patient-centred care in Family Health Teams: a qualitative study
}

\author{
Judith Belle Brown PhD, Bridget L. Ryan PhD, Cathy Thorpe MA
}

\section{Abstract}

Background: Patient-centred care, access to care, and continuity of and coordination of care are core processes in primary health care delivery. Our objective was to evaluate how these processes are enacted by 1 primary care model, Family Health Teams, in Ontario.

Methods: Our study used grounded theory methodology to examine these 4 processes of care from the perspective of health care providers. Twenty Family Health Team practice sites in Ontario were selected to represent maximum variation (e.g., location, year of Family Health Team approval). Semi-structured interviews were conducted with each participant. A constant comparative approach was used to analyze the data.

Results: Our final sample population involved 110 participants from 20 Family Health Teams. Participants described how their Family Health Team strived to provide patient-centred care, to ensure access, and to pursue continuity and coordination in their delivery of care. Patient-centred care was provided through a variety of means forging the links among the other processes of care. Participants from all teams articulated a commitment to timely access, spontaneously expressing the importance of access to mental health services. Continuity of care was linked to both access and patient-centred care. Coordination of care by the team was perceived to reduce unnecessary walk-in clinic and emergency department visits, and facilitated a smoother transition from hospital to home.

Interpretation: These 4 processes of patient care were inextricably linked. Patient-centred care was the focal point, and these processes in turn served to enhance the delivery of patient-centred care.

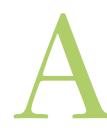

recent report by the European Commission Expert Panel on Effective ways of Investing in Health described a primary care system as "universally accessible, integrated, person-centred, comprehensive ... and provided by a team of professionals accountable for addressing a large majority of personal health needs." "These processes of care were heralded by authors over a decade $\operatorname{ago}^{2,3}$ and continue to be emphasized in current research. ${ }^{4-7}$ In particular, patient-centredness, access, continuity and coordination of care are hallmarks of primary care models worldwide. ${ }^{8}$

One model of primary care is the interprofessional Family Health Team (FHT) in Ontario, which was launched in 2005. Now numbering 200, FHTs provide care for more than 3 million Ontarians (about 22\% of the provincial population). ${ }^{9,10}$ The FHTs include family physicians and other primary care professionals, most commonly nurses, nurse practitioners, social workers, dietitians and pharmacists, as well as administrative support staff. ${ }^{10}$ The principal goals of the provincially funded FHTs are improved access, quality and comprehen- siveness of care (with an emphasis on chronic disease management, health promotion and disease prevention), interdisciplinary teamwork, patient engagement, and integration and coordination of care. ${ }^{10}$

We defined the 4 processes of care as follows: patient-centred care highlights the patient-provider relationship and caring for the whole person, not just the disease. We defined access as the ability of a patient to obtain appointments and care after hours at the FHT site. Continuity of care involved both relational and informational collaboration provided by the interprofessional FHT. We defined coordination of care

\section{Competing interests: None declared.}

This article has been peer reviewed.

Correspondence to: Judith Brown, Judith.Brown@schulich.uwo.ca CMAJ Open 2016. DOI:10.9778/cmajo.20150128 
as integrated care, including transitions from hospital to home. Although much is known about these individual processes of care, ${ }^{11-17}$ less is understood about if, and how, these processes are related. Therefore, we sought to provide a further understanding of how these processes of care are enacted by FHTs.

\section{Methods}

We used grounded theory methodology to examine specific processes of care for patients of the FHTs from the perspective of their health care providers. ${ }^{18}$

\section{Participant recruitment}

Twenty FHT practice sites were recruited with the administrative support of the Ontario College of Family Physicians (OCFP). Sites were selected to represent maximum variation in terms of location (urban and rural), year of FHT approval, mix of health professionals and practice configuration (i.e., single or multisite). The interview participants were recruited by telephone and email from each of the 20 participating practices, most often by the designated contact person for those sites. They were asked to recruit participants who would reflect the overall team composition. Informed consent was received from each participant before the interview began. Confidentiality was assured.

\section{Data collection}

We conducted semi-structured, in-depth interviews with each participant. A list of interview questions is in Appendix 1 (available at www.cmajopen.ca/content/4/2/E271/suppl/DC1). These questions explored participants' ideas and perceptions regarding continuity, coordination of care including transitions from hospital to home. We held interviews in a private space at the practice site. Interviews usually were about 30 minutes, and Interviews were audio-recorded and transcribed verbatim. We used NVivo software for all data analyses. Although saturation was achieved by the time of the interviews at the 12th site, we were committed to complete data collection and analysis for all 20 sites to ensure geographic variation.

\section{Data analysis}

We analyzed the data using 3 specific steps: open coding, axial coding and selective coding. ${ }^{18}$ For the first phase of analysis, each transcript was independently reviewed and coded by 3 researchers to determine the key concepts emerging from the data. The researchers then met to examine their independent coding, which culminated in a consensus that informed the development of the coding template and axial coding. Next, the 3 researchers applied selective coding to generate summaries for each main theme with exemplar quotes. Finally, a matrix was developed that combined all themes, which facilitated a constant comparison of the data.

The trustworthiness and credibility of the analysis was ensured by using audio-recording and verbatim transcripts, independent and team analysis, and detailed field notes following each practice visit. A commitment to reflexivity con- sidered how the researchers' professional backgrounds (i.e., social work, epidemiology and sociology), particularly in the coding and interpretation of the data, could influence the findings. ${ }^{19}$

\section{Ethics approval}

Ethics approval was received from the Health Sciences Research Ethics Board of Western University (no. 18745E).

\section{Results}

Our study involved 110 participants from 20 FHT sites. Team sizes ranged from 9 to 80 members. Participant and practice site characteristics are described in Table 1 and Table 2 , respectively.

Through the participants' descriptions of how their FHTs provided patient-centred care, access, continuity and coordination, an important theme emerged of how these 4 processes of care were inextricably linked. Patient-centred care was the focal point of these inter-related processes.

\section{Patient-centred care}

A variety of methods were used to provide patient-centred care, which linked the processes of care. Practical and instrumental activities reflecting patient-centred care included improved access and continuity, and attention to issues of coordination and smooth transitions in care.

I think what's probably patient-centred is certainly the accessibility. ... We often hear from patients really appreciating the availability of care so I think that's very patient-centred. We're trying to offer day time and evening appointments in mental health - I think that's patient-centred. (Social worker, no. 3)

Being patient-centred was also linked to having access to a variety of health care professionals on the team. "What's fabulous about our team is that we really provide holistic care. Having all the different health care professionals here and being able to refer to them is a real luxury ...." (Nurse, no. 1)

In addition, being patient-centred was also described as providing care that fostered continuity across the entire team by advocating whole person care. This also illustrated the connections among patient-centred care, access and continuity.

The majority of us in the group will really genuinely bring up the patient perspective, patient issue, and all of the demographics and psychosocial issues around that patient and then it's clear to me that we're really trying to be very patient focused. (Nurse practitioner, no. 87)

Coordination of care, including prevention and health promotion activities integral to patient-centred care, were shown in the following quotation:

Having the client play an active role in their health care, so instead of saying, "Okay, you need to do this, and you need to take care of this," we do a lot of motivational interviewing with the client around what their concerns are, what their goals are and what support they would like. (Social worker, no. 26) 


\section{Access}

Participants from all FHTs articulated their commitment to ensuring timely access to care. Teams approached access in various ways. Some teams offered advanced access: "We have amazing access and so the way that we do that is we have an advanced access schedule, so basically anybody who needs to get in today, gets in today." (Family physician, no. 88). Other teams provided access in what could be termed "hybrid access mod- els," where, within the teams, access could include extended hours, or open space in the appointment schedule of the physician or nurse practitioner. Access was described as the following:

I do advanced access so that means really a mini-meeting almost every morning to look at the day sheet and look at what the nurse practitioner is up to ... and I talk with my receptionist about what we can do, so it's very open that way. (Family physician, no. 10)

\begin{tabular}{|lc|}
\hline Table 1: Participant characteristics & \\
\hline Characteristic & $\begin{array}{c}\text { No. }(\%) \text { of participants* } \\
n=110\end{array}$ \\
\hline Age, yr; mean \pm SD (range) & $41 \pm 11.6(23-72)$ \\
\hline $\begin{array}{l}\text { Time in current position, yr; mean } \pm \text { SD } \\
\text { (range) }\end{array}$ & $5.5 \pm 6.7(<1-36$ mo) \\
\hline Sex & \\
\hline Male & $21(19.1)$ \\
\hline Female & $89(80.9)$ \\
\hline Professional affiliation & $28(25.5)$ \\
\hline Family physician & $16(14.5)$ \\
\hline Nurse & $12(10.9)$ \\
\hline Nurse practitioner & $11(10.0)$ \\
\hline Executive director & $11(10.0)$ \\
\hline Social worker & $9(8.2)$ \\
\hline Dietitian & $8(7.3)$ \\
\hline Administrative assistant & $6(5.5)$ \\
\hline Management personnel & $3(2.7)$ \\
\hline Pharmacist & $2(1.8)$ \\
\hline Psychologist & $2(1.8)$ \\
\hline Physician assistant & $1(0.9)$ \\
\hline Occupational therapist & $1(0.9)$ \\
\hline Respiratory therapist & \\
\hline *Unless otherwise specified. & \\
\hline & \\
\hline
\end{tabular}

\begin{tabular}{|lc|}
\hline Table 2: Practice site characteristics \\
\hline Characteristic & $\begin{array}{c}\text { No. }(\%) \text { of } \text { sites }^{*} \\
n=20\end{array}$ \\
\hline No. of years as a Family Health Team, mean \pm SD (range) & $5.14 \pm 1.96(<1-8)$ \\
\hline No. of team members, mean \pm SD (range) & $37 \pm 25(9-80)$ \\
\hline Location & $13(65.0)$ \\
\hline Urban & $7(35.0)$ \\
\hline Rural & $11(55.0)$ \\
\hline Configuration & $9(45.0)$ \\
\hline Single site & \\
\hline Multiple sites & \\
\hline *Unless otherwise specified. & \\
\hline
\end{tabular}


Participants spontaneously expressed the importance of access to mental health services in FHTs. "We have two social workers who do a phenomenal job, they have taken a huge load as they are a great help to us in the sort of social and emotional medicine area." (Family physician, no. 93). Access was not only described as the availability of mental health services in general but also responsiveness to acute crises identified by other providers. "When a patient comes in and they're in a mental health crisis, I can go directly and speak to one of the social workers and say ... 'this is what's going on, these are the issues, I need these resources', so they're right there." (Nurse practitioner, no. 4). The provision of mental health services was viewed as an alternative to services in the community with long waiting lists and additional cost. "So I do tend to see people where they don't have any other option and they need some immediate assistance." (Social worker, no. 90).

However, the concern about long waiting lists was beginning to impact the provision of mental health services at the sites for 2 primary reasons. The first reflected how the demand had been exponentially growing: "I think it's always going to be a question of demand exceeding supply, sadly." (Pharmacist, no. 50). The second reason was the tension occurring between the provision of short- versus long-term psychotherapy:

It's an ethical thing [in terms of duration of care]. You want to do good work but on the other side, if you're keeping somebody too long [in therapy], then somebody [else] isn't getting any care. So it's a balancing act. (Psychologist, no. 43)

Despite these challenges, having mental health counsellors affiliated with the team was highly valued. "Definitely the social worker is the biggest bang for the buck, in terms of having them on hand to give us a hand to manage patients." (Family physician, no. 37).

Our findings show how access is now being addressed from a patient-centred perspective.

\section{Continuity}

The findings revealed a link between access and continuity: "Advanced access is a tool that ensures continuity. If my patients don't need to see the doctors on call all the time because they can see me, then that's continuity." (Family physician, no. 10). However, some participants acknowledged the fine balance between providing access while ensuring continuity: "Their follow-up is with their own provider. So that balance of continuity and access I think is very balanced here." (Executive director, no. 57).

Continuity of care and patient-centred care were also linked as the following participant articulated:

I think that continuity of care goes closely with patient-centred care because if you have a patient coming in having to tell their story over and over and over to different people that makes it difficult for everyone ... they've shared their story with me and they've got to know me and trust me and we've developed a relationship so they have that continuity. (Physician assistant, no. 81)

Continuity of care was often described as "one-stop shopping":
What I see and what a lot of the patients see is being the great thing about a family health team is that it's one-stop shopping, all their notes are in the same place and we do work as a team. (Social worker, no. 46)

Working as a team was viewed as enhancing continuity: "Anytime you can put more than one discipline together in the same building, the continuity and quality of the care should ideally be increased." (Occupational therapist, no. 84). Furthermore, continuity and collaboration could improve the delivery of patient-centred care and, ultimately, patient outcomes.

Continuity of care or collaboration of care, our FHT team supports that $100 \%$ so their aim is not to "take over" a patient from a physician, their aim is to lend a hand and extend the care for the patient on the behalf of the physician. Collaboration is really important so they work together as a team to support that patient's health. (Executive director, no. 104)

\section{Coordination}

Participants perceived that the care they were now able to provide through an interdisciplinary team approach reduced unnecessary walk-in clinic and emergency department visits, and facilitated a smoother transition from hospital to home. "We set certain goals for our family health team. ... We've pretty much come down to zero with outside use [walk-in clinics] ... our next big goal is we're trying to reduce ER visits." (Family physician, no. 22)

Some teams were able to combine team members' scopes of practice in enacting mechanisms to support and enhance patient transitions. These joint activities facilitated the team's ability to be patient-centred in their care plan.

As for hospital discharges, we do have an organized system. So for example, a patient has been in the hospital for a week or 2 and has been discharged, the doctor will know within 48 hours and either myself or the nurse will call and follow up with the patient once they've been discharged home. Usually within the first couple of days they will have a follow up appointment with one of the doctors here but in the meantime we always call to see if there's any problems - "Do you have a follow-up appointment booked? Do you have any concerns about your medication? Would you like our pharmacist to call you because now they've changed all your medications around? Do you have enough care at home?" (Nurse practitioner, no. 36)

However, challenges were encountered when teams were not notified about their patients' discharge from hospital. "The transition from hospital to home and that care that needs to be involved is weak right now. There isn't a strong link. We don't know when our patients are in the hospital." (Dietician, no. 13). Despite these challenges, teams continued to strive for optimal patient transitions. "The transitions of care ... has to be a priority because it accounts for a lot of mistakes and needless consequences." (Family physician, no. 66)

Participants articulated how collaborative interdisciplinary practice facilitated coordination and patient-centred care.

"We collaborate together. It is really a step forward. ... Sometime we do joint home visits. ... If I know the patient, or I have seen the patient and she [other health care provider] hasn't, a lot of 
time I will go out with her intiallly. She may be a stranger but it is a way to [indicate] this is my team member and a way to show the patient and the family that we do work together." (Nurse, no. 25)

\section{Interpretation}

Our study explored 4 processes of care: patient-centred care. access, continuty and coordination. Although these processes have been reported in prior research on FHTs, what is unique in our study is the links among the processes..$^{5-7}$ In particular, how patient-centred care was the focal point that brought the other processes together, and how they in turn served to enhance the delivery of patient-centred care.

This finding is important, given the strong evidence that patient-centred care has a positive influence on patient outcomes such as patient self-reported health, patient adherence, physiologic health and patient equity. ${ }^{12,15,17}$ For some participants, patient-centred care was more instrumental and included improved access and maintenance of continuity within the team setting. In addition, coordination and facilitation of transitions of care were not boilerplate but geared to patients' specific needs and preferences, which are hallmarks of patient-centred care. ${ }^{20}$ Other participants highlighted the patient-provider relationship, articulating a commitment to caring for the whole person not just the disease, which is a basic tenet of patient-centred care. ${ }^{20}$

Improved access to care is a central mandate for FHTs. Our study and other research ${ }^{5,21,22}$ have shown that this is being achieved, albeit through various approaches. Our study participants' unsolicited emphasis of the added value of unique access to mental health services within their FHTs was a new and important finding. This finding supports the link between access and patient-centred care and is noteworthy given that prior research showed an association between patient-centred care and positive mental health outcomes. ${ }^{17}$ Research on the integration of mental health services into primary care practices has been limited to the experiences of shared care models in limited geographic locations, ${ }^{21,22}$ whereas our findings reflect 20 FHTs across Ontario.

Having mental health services available extended beyond accessibility to include timely responses to patients in crisis. However, given the demand for mental health services, the need overwhelmed the ability to provide timely access, which resulted in long waiting lists. This issue requires remediation and could be addressed through creative service provision, such as cognitive behavioural therapy group sessions for patients with anxiety.

Those who disagree with interdisciplinary team work have anecdotaly warned that continuity of care will be forfeited in this setting. However, our findings suggest the opposite the team's commitment to ensuring continuity, while at the same time providing timely access, is achievable if there is active collaboration among team members.

A recent systematic review reported that coordination can result in both positive patient and system outcomes. ${ }^{13}$ The commitment to providing coordinated care by the particpants involved in our study was, in many instances, directed toward reducing the use of resources outside the FHT, such as walkin clinics or the emergency department. The greatest challenges the FHTs faced were the logistical and bureaucratic barriers they encountered. For example, it was often impossible to facilitate a patient's transition from hospital to home if the FHT had not been notified of the patient's discharge or admission. The changes needed to ameliorate this situation are beyond the scope of each FHT and would require significant systemic changes.

\section{Limitations}

We only evaluated 4 processes of care. We did not evaluate other patient care processes, such as patient engagement and comprehensiveness of care, which are also goals for FHTs.

Our data analysis did not examine the power differential experienced by different professional groups on the teams and is a limitation. In addition, we only evaluated FHTs in Ontario, which limits the transferability of our findings to other primary care models.

\section{Conclusion}

We have illustrated the links between these 4 processes of patient care and the dynamic interaction among them. Underpinning these processes is the FHT's commitment to patient-centred care. Further research may explore the impact of these processes on patient outcomes and health care utilization. Future research should also include patients' perceptions and experiences of these processes of care, because they may differ from those of health care providers.

\section{References}

1. The Lancet. Making primary care people-centred: a 21st century blueprint Lancet 2014;384:281.

2. Craigie FC Jr, Hobbs RF III. Exploring the organizational culture of exemplary community health center practices. Fam Med 2004;36:733-8.

3. Grumbach K, Bodenheimer T. Can health care teams improve primary care practice? 7AMA 2004;291:1246-51.

4. Howard M, Brazil K, Akhtar-Danesh N, et al. Self-reported teamwork in family health team practices in Ontario. Can Fam Physician 2011;57:e185-91.

5. Goldman J, Meuser J, Roger J, et al. Interprofessional collaboration in family health teams. Can Fam Physician 2010;56:e368-74.

6. Conn GL, Oandasan IF, Creede C, et al. Creating sustainable change in the interprofessional academic primary care setting: an appreciative inquiry approach. FRIPE 2010;1:284-300.

7. Bodenheimer T, Ghorob A, Willard-Grace R, et al. The 10 building blocks of high-performing primary care. Ann Fam Med 2014;12:166-71.

8. Starfield B, Shi L, Macinko J. Contribution of primary care to health systems and health. Milbank Q 2005;83:457-502.

9. Hutchison B, Glazier R. Ontario's primary care reforms have transformed the local care landscape, but a plan is needed for ongoing transformation. Health Aff 2013;32:695-703

10. Leading Practices Database - Family Health Teams. Ottawa: Accreditation Canada; 2013. Available: www.accreditation.ca/family-health-teams (accessed 2014 Aug. 25).

11. Haggerty JL, Reid RJ, Freeman GK, et al. Continuity of care: a multidiscipinary review. BM7 2003;327:1219-21.

12. Rao JK, Anderson LA, Inui TS, et al. Communication interventions make a difference in conversations between physicians and patients: a systematic review of the evidence. Med Care 2007;45:340-9.

13. Smith SM, Allwright S, O'Dowd T. Effectiveness of shared care across the interface between primary and specialty care in chronic disease management. Cochrane Database Syst Rev 2007; (3):CD004910.

14. Howard M, Goertzen J, Kaczorowski J, et al. Emergency department and walk-in clinic use in models of primary care practice with different afterhours accessibility in Ontario. Healthc Policy 2008;4:73-88.

15. Dwamena F, Holmes-Rovner M, Gaulden CM, et al. Interventions for providers to promote a patient-centred approach in clinical consultations. Cochrane Database Syst Rev 2012;12:CD003267. 
16. Glazier RH, Kopp A, Schultz SE, et al. All the right intentions but few of the desired results: lessons on access to primary care from Ontario's patient enrolment models. Healthc Q 2012;15:17-21.

17. Jani B, Bikker AP, Higgins M, et al. Patient centrednes and the outcome of primary care consultations with patients with depression in areas of high and low socioeconomic deprivation. Br 7 Gen Pract 2012;62:e576-81.

18. Charmaz K. Constructing grounded theory: a practical guide through qualitative analysis. Thousand Oaks (CA): Sage; 2014

19. Malterud K. Qualitative research: standards, challenges and guidelines. Lancet 2001;358:483-8.

20. Stewart M, Brown JB, Weston WW, et al. Patient-centered medicine transforming the clinical method. London (UK): Radcliffe Publishing; 2014.

21. Kates N, McPherson-Doe C, George L. Integrating mental health services within primary care settings: the Hamilton Family Health Team. 7 Ambul Care Manage 2011;34:174-82.

22. Haggarty JM, Jarva JA, Cernovsky Z, et al. Wait time impact of co-located primary care mental health services: the effect of adding collaborative care in Northern Ontario. Can 7 Psychiatry 2012;57:29-33.

Affiliations: Departments of Family Medicine (Brown, Ryan, Thorpe), and Epidemiology and Biostatistics (Ryan), Schulich School of Medicine and Dentistry, Western University; School of Social Work (Brown), King's University College, Western University, London, Ont.

Contributors: Judith Brown designed this qualitative study. All of the authors collected and analyzed the data, contributed to writing the manuscript and reviewed it critically for intellectual content, gave final approval for the version to be published and agreed to act as guarantors of the work.

Funding: The authors acknowledge funding and support from the Ontario Ministry of Health and Long-Term Care and the Ontario College of Family Physicians. The views expressed are those of the authors and do not necessarily reflect those of the Ministry or the College. Bridget Ryan is funded by the Canadian Institutes for Health Research Community-based Primary Health Care Innovation Team, Patient-centred innovations for persons with multimorbidity.

Supplemental information: For reviewer comments and the original submission of this manuscript, please see www.cmajopen.ca/content/4/2/ E271/suppl/DC1 